\title{
PERFIL BIOQUÍMICO SÉRICO DE VACAS DAS RAÇAS NELORE E GIROLANDO CRIADAS NO ESTADO DO MARANHÃO
}

\section{SERUM BIOCHEMICAL PROFILE OF NELLORE AND GIROLANDO COWS RAISED IN STATE OF MARANHÃO}

\author{
Washington Luis Ferreira Conçeição ${ }^{1^{*}}$ ORCID - http://orcid.org/0000-0003-1168-8894 \\ Danilo Rodrigues Barros Brito ${ }^{1}$ ORCID - http://orcid.org/0000-0001-5073-3681 \\ Thaís Gomes Rocha² ORCID - http://orcid.org/0000-0002-0434-8210 \\ Daniela Gomes da Silva² ORCID - http://orcid.org/0000-0002-5232-9516 \\ Daniel Praseres Chaves² ORCID - http://orcid.org/0000-0002-5320-1469 \\ José Jurandir Fagliari² ORCID - http://orcid.org/0000-0002-6232-6917 \\ ${ }^{1}$ Instituto Federal do Maranhão, São Luís, MA, Brasil. \\ ${ }^{2}$ Faculdade de Ciências Agrárias e Veterinárias da UNESP, Jaboticabal, SP, Brasil \\ "Autor para correspondência - was_con@hotmail.com
}

\section{Resumo}

O objetivo do trabalho foi avaliar a atividade sérica da aspartato aminotransferase (AST), fosfatase alcalina (ALP), creatina quinase (CK), gamaglutamiltransferase (GGT) e as concentrações séricas de albumina, bilirrubina, cálcio total e ionizado, colesterol, creatinina, fósforo, magnésio, potássio, proteína total, sódio, triglicérides e ureia de vacas das raças Nelore $(n=120)$ e Girolando $(n=120)$ clinicamente saudáveis, com 24 a 36 meses de idade, utilizando-se espectrofotômetro semiautomático e analisador automático de íons. A influência da raça foi verificada na avaliação da atividade da $\mathrm{CK}$, cujos valores foram maiores em vacas da raça Nelore $(87,5 \mathrm{U} / \mathrm{L})$, quando comparados com aqueles de vacas Girolando (68,6 U/L). Os teores séricos de creatinina (Crea), bilirrubina total (BT), bilirrubina indireta $(\mathrm{BI})$ e cálcio ionizado também foram influenciados pela raça, e os valores obtidos em vacas da raça Nelore (Crea: 1,61 mg/dL, BT: 0,28 mg/dL e BI: 0,19 mg/dL) foram superiores aos apresentados pelas vacas Girolando (BT: $1,47 \mathrm{mg} / \mathrm{dL}, \mathrm{BD}: 0,23 \mathrm{mg} / \mathrm{dL}$ e BI: $0,14 \mathrm{mg} / \mathrm{dL}$ ), exceto para a concentração sérica de cálcio ionizado (Nelore: 0,66 mMol/L e Girolando: 0,73 $\mathrm{mMol} / \mathrm{L}$ ). Os resultados obtidos evidenciaram a influência do fator racial em alguns parâmetros bioquímicos e, portanto, este deve ser levado em consideração para a correta interpretação de exames laboratoriais.

Palavras-chave: bovino, bioquímica clínica, influência racial, valores de referência.

\begin{abstract}
The aim of this research was to evaluate serum activities of aspartate aminotransferase (AST), alkaline phosphatase (ALP), creatine kinase (CK), gamma-glutamyltransferase (GGT), and on serum concentrations of albumin, bilirubin, total and ionized calcium, cholesterol, creatinine, phosphorus, magnesium, potassium, total protein, sodium, triglycerides, and urea of Nellore $(\mathrm{n}=120)$ and Girolando $(n=120)$ healthy cows, aged 24 to 36 months, using a semiautomatic spectrophotometer and automatic ion analyzer. Assessment of enzyme activity showed the influence of racial factors in the results of $\mathrm{CK}$, the values of Nellore cows $(87.5 \mathrm{U} / \mathrm{L})$ being higher than the Girolando cows $(68.6 \mathrm{U} / \mathrm{L})$. Serum levels of creatinine (Crea), total bilirubin (TB), unconjugated bilirubin (UB) and ionized calcium
\end{abstract}


were also influenced by breed, and the values obtained for the Nellore cows (Crea: $1.61 \mathrm{mg} / \mathrm{dL}$, TB: $0.28 \mathrm{mg} / \mathrm{dL}$ and UB: $0.19 \mathrm{mg} / \mathrm{dL}$ ) were higher than those observed for Girolando cows (Crea: 1.47 $\mathrm{mg} / \mathrm{dL}, \mathrm{TB}: 0.23 \mathrm{mg} / \mathrm{dL}$ and UB: $0.14 \mathrm{mg} / \mathrm{dL}$ ), except for ionized calcium (Nellore: $0.66 \mathrm{mMol} / \mathrm{L}$ and Girolando: $0.73 \mathrm{mMol} / \mathrm{L}$ ). The results evidenced the influence of racial factor on some biochemical parameters, and, therefore, should be taken into consideration for correct interpretation of laboratory tests.

Keywords: bovine, clinical biochemistry, racial influence, reference values.

Recebido em 29 janeiro de 2015.

Aceito em: 08 de fevereiro de 2019.

\section{Introdução}

O estado do Maranhão possui o segundo maior rebanho bovino da região Nordeste do Brasil (7.653.870 de bovinos), com predomínio de criações extensivas voltadas para a produção de carne e/ou leite ${ }^{(1)}$, com destaque para os animais das raças Nelore e Girolando, bem adaptadas às condições climáticas dessa região ${ }^{(2)}$.

O perfil bioquímico sérico constitui um excelente subsídio ao diagnóstico de distúrbios metabólicos, pois reflete a integridade celular e a função orgânica, permitindo avaliar lesões teciduais, transtornos na função de órgãos, adaptação dos animais diante de desafios nutricionais e fisiológicos e desequilíbrios metabólicos ${ }^{(3)}$. A avaliação clínica de rebanhos com problemas reprodutivos e de produção também pode ser complementada pela análise do perfil bioquímico dos animais ${ }^{(4)}$.

No caso específico dos bovinos, quer sejam taurinos ou zebuínos, a realização e a interpretação de testes bioquímicos possibilitam determinar o prognóstico e avaliar a progressão e a gravidade de doenças, principalmente aquelas com repercussões hepáticas e/ou renais. No entanto, para uma adequada interpretação de exames laboratoriais, é importante dispor de valores de referência apropriados para a região e a população, em razão das diferenças raciais, etárias, climáticas, de manejo e de metodologias utilizadas pelos pesquisadores ${ }^{(5,6)}$.

Contudo, os médicos veterinários brasileiros ainda utilizam padrões estabelecidos em países do hemisfério norte como valores de normalidade ${ }^{(7,8)}$, o que reforça a necessidade de pesquisas sobre os valores de referência para as raças bovinas criadas no território nacional, situado, em sua grande maioria, na faixa tropical do planeta.

Dessa forma, o objetivo deste estudo foi avaliar a influência dos fatores raciais nos parâmetros bioquímicos séricos de fêmeas bovinas sadias das raças Nelore e Girolando, criadas no estado do Maranhão.

\section{Material e métodos}

O estudo foi aprovado pela Comissão de Ética no Uso de Animais (CEUA) da FCAV/UNESP (protocolo $\left.n^{\circ} 007780 / 09\right)$. Foram examinadas amostras de sangue de 240 fêmeas bovinas clinicamente sadias, após exame físico (frequência cardíaca, respiratória, movimentos ruminais e temperatura retal) (9) e 
a constatação de valores hematológicos (eritograma, leucograma e contagem de plaquetas) dentro do intervalo de normalidade para a espécie ${ }^{(10)}$, negativas nos testes de brucelose e tuberculose, com 24 a 36 meses de idade, não prenhes e não lactantes, sendo 120 da raça Nelore e 120 da raça Girolando, criadas na região Centro-Oeste do estado do Maranhão. Os animais eram mantidos em pastagens de Brachiaria brizantha, com suplementação de sal mineral comum.

Para a realização das análises bioquímicas, amostras $(20 \mathrm{~mL})$ de sangue foram obtidas por punção jugular e acondicionadas em frascos a vácuo, sem anticoagulante. Após a coleta, as amostras foram centrifugadas a $1.000 \mathrm{x}$ g, durante 15 minutos. Após sinérese, o soro obtido foi fracionado em alíquotas e mantido a $-20{ }^{\circ} \mathrm{C}$ até o momento das análises.

Foram avaliadas as atividades séricas das enzimas aspartato aminotransferase (AST) (método cinético UV-IFCC), fosfatase alcalina (ALP) (método de Bowers e McComb modificado), creatina quinase (CK) (método cinético UV-IFCC) e gamaglutamiltransferase (GGT) (método de Szasz modificado), bem como os teores séricos de albumina (método do verde de bromocresol), bilirrubina total e direta (método de Sims-Horn), cálcio total (método CPC), colesterol (método enzimático de Trinder), creatinina (método de picrato alcalino -Jaffé), fósforo (método de Daly e Ertingshausen modificado), magnésio (método de Magon sulfonado), proteína total (método do biureto), triglicérides (método enzimático de Trinder) e ureia (método enzimático UV). Para a realização dos testes, foram utilizados reagentes comerciais (Labtest, Labtest Diagnóstica S.A., Lagoa Santa, Minas Gerais, Brasil); as leituras foram realizadas em espectrofotômetro semiautomático (Labquest, Labtest Diagnóstica S.A., Lagoa Santa, Minas Gerais, Brasil), em comprimentos de onda específicos para cada parâmetro analisado. Para a avaliação dos teores de cálcio ionizado, sódio e potássio, empregou-se o método de íons seletivos (9180 Electrolyte Analyzer, Roche Diagnostics, Mannheim, Germany). O teor de bilirrubina indireta foi calculado pela diferença aritmética entre as concentrações de bilirrubina total e direta.

Para o estudo estatístico, realizou-se análise de variância (ANOVA) para um delineamento inteiramente casualizado. Os contrastes entre pares de médias foram avaliados por meio do teste t de Student; as diferenças foram consideradas significativas quando $\mathrm{P}<0,05(11)$. A ANOVA e o teste de Student foram realizados mediante o uso do programa estatístico computarizado Statistical Analysis System (SAS - Versão 9.1.3) $)^{(12)}$.

\section{Resultados e discussão}

De acordo com os resultados obtidos, não houve diferença na atividade sérica das enzimas AST, ALP e GGT entre as fêmeas bovinas das raças Nelore e Girolando (Tabela 1). No entanto, as fêmeas Nelore apresentaram valores superiores de CK (87,5 U/L), quando comparados aos das vacas Girolando (68,6 U/L). Como teste auxiliar de diagnóstico, a elevação da atividade sérica da CK é considerada indicador de lesão muscular ${ }^{(13)}$. Diversos pesquisadores relataram fatores que induzem à elevação da atividade dessa enzima no soro sanguíneo dos animais, dentre os quais se destacam esforço físico, traumatismo durante o transporte, injeção intramuscular e decúbito prolongado ${ }^{(14-16)}$. É provável que a diferença verificada neste estudo se deva ao comportamento mais reativo dos bovinos da raça Nelore, que exercem maior esforço muscular no momento da coleta das amostras de sangue.

A ausência de diferenças nas atividades séricas das enzimas AST, ALP e GGT em função da raça difere dos achados de Souza et al. ${ }^{(8)}$, os quais verificaram maior atividade na AST em bovinos da raça Jersey (49,3 U/L), quando comparados a animais da raça Holandesa (34,8 U/L), de diversas 
faixas etárias de propriedades produtoras de leite do estado de São Paulo, e de Cardoso et al. ${ }^{(17)}$, que observaram maior atividade da ALP em bovinos machos da raça Nelore (161,2 U/L) e Curraleiro (155,1 U/L), em comparação com animais da raça Pantaneiro (84,1 U/L), com aproximadamente 24 meses de idade e mantidos em confinamento no estado de Goiás. Por outro lado, Fagliari et al. ${ }^{(18)}$ também não constataram diferença na atividade das enzimas AST, ALP e GGT entre bovinos machos e fềmeas entre um e oito anos de idade das raças Nelore (AST: 46,2 U/L, ALP: 78,1 U/L e GGT: 17,2 U/L) e Holandesa (AST: 40,0 U/L, ALP: 82,0 U/L e GGT: 16,2 U/L), mantidos em pastagens de Brachiaria decumbens e com suplementação mineral no estado de São Paulo.

Tabela 1. Médias e desvios padrão de parâmetros bioquímicos séricos de fêmeas bovinas sadias das raças Nelore e Girolando, criadas no estado do Maranhão, Brasil

\begin{tabular}{|c|c|c|}
\hline \multirow{2}{*}{ Parâmetros } & \multicolumn{2}{|c|}{ Raças } \\
\hline & Nelore $(n=120)$ & Girolando $(n=120)$ \\
\hline Albumina (g/dL) & $2,52 \pm 0,51$ & $2,42 \pm 0,44$ \\
\hline Aspartato aminotransferase (U/L) & $58,5 \pm 18,2$ & $59,7 \pm 17,5$ \\
\hline Bilirrubina direta (mg/dL) & $0,09 \pm 0,05$ & $0,09 \pm 0,04$ \\
\hline Bilirrubina indireta $(\mathrm{mg} / \mathrm{dL})$ & $0,19 \pm 0,15^{\mathrm{A}}$ & $0,14 \pm 0,09^{\mathrm{B}}$ \\
\hline Bilirrubina total (mg/dL) & $0,28 \pm 0,16^{\mathrm{A}}$ & $0,23 \pm 0,08 \mathrm{~B}$ \\
\hline Cálcio ionizado $(\mathrm{mMol} / \mathrm{L})$ & $0,66 \pm 0,14^{A}$ & $0,73 \pm 0,18^{B}$ \\
\hline Cálcio total (mg/dL) & $8,63 \pm 1,45$ & $8,71 \pm 1,27$ \\
\hline Colesterol (mg/dL) & $126 \pm 41,0$ & $136 \pm 47,9$ \\
\hline Creatina quinase $(\mathrm{U} / \mathrm{L})$ & $87,5 \pm 56,3^{A}$ & $68,6 \pm 43,4^{B}$ \\
\hline Creatinina (mg/dL) & $1,61 \pm 0,41^{A}$ & $1,47 \pm 0,32^{B}$ \\
\hline Fosfatase alcalina (U/L) & $76,7 \pm 43,2$ & $73,7 \pm 40,9$ \\
\hline Fósforo $(\mathrm{mg} / \mathrm{dL})$ & $5,34 \pm 1,35$ & $5,18 \pm 1,49$ \\
\hline Gamaglutamiltransferase (U/L) & $20,2 \pm 9,25$ & $22,1 \pm 7,54$ \\
\hline Magnésio (mg/dL) & $2,49 \pm 0,51$ & $2,53 \pm 0,50$ \\
\hline Potássio (mMol/L) & $5,91 \pm 1,47$ & $5,95 \pm 1,57$ \\
\hline Proteina total $(\mathrm{g} / \mathrm{dL})$ & $7,70 \pm 1,24$ & $7,79 \pm 1,00$ \\
\hline Sódio $(\mathrm{mMol} / \mathrm{L})$ & $136 \pm 8,93$ & $134 \pm 8,45$ \\
\hline Triglicérides $(\mathrm{mg} / \mathrm{dL})$ & $24,0 \pm 8,59$ & $25,7 \pm 7,06$ \\
\hline Ureia (mg/dL) & $21,5 \pm 12,0$ & $19,0 \pm 10,0$ \\
\hline
\end{tabular}

Médias seguidas de letras maiúsculas diferentes na mesma linha diferem entre si pelo teste $t$ de Student $(P>0,05)$.

Não se constatou influência da raça nos teores séricos de albumina (Alb) e de proteína total (PT) (Tabela 1), semelhante ao relatado por Fagliari et al. ${ }^{(18)}$, ao compararem animais das raças Nelore (Alb: 3,29 g/dL e PT: 7,04 g/dL) e Holandesa (Alb: 3,39 g/dL e PT: 7,16 g/dL), e por Cardoso et al. ${ }^{(17)}$, avaliando animais das raças Curraleiro (Alb: 3,06 g/dL e PT: 7,85 g/dL), Pantaneiro (Alb: 3,11 g/dL e PT: 8,40 g/dL) e Nelore (Alb: 3,52 g/dL e PT: 8,94 g/dL). Entretanto, em estudo realizado por Souza et al. ${ }^{(8)}$, a concentração sérica de PT foi superior em bovinos da raça Holandesa $(6,82 \mathrm{mg} / \mathrm{dL})$, em comparação com bovinos da raça Jersey $(6,37 \mathrm{mg} / \mathrm{dL})$, enquanto o teor sérico de Alb apresentou comportamento inverso (Holandesa: 3,08 g/dL e Jersey: 3,24 g/dL, respectivamente).

A concentração de ureia não foi influenciada pela raça, diferentemente do verificado para os teores de creatinina, cujos maiores valores foram apresentados pelos animais da raça Nelore $(1,61 \mathrm{mg} /$ dL) (Tabela 1). A maior concentração sérica de creatinina apresentada pelos animais da raça Nelore provavelmente está relacionada à maior massa muscular dos animais dessa raça, quando comparados aos da raça Girolando, visto que o teor sérico de creatinina de um indivíduo relaciona-se ao volume 
de massa muscular, sendo, portanto, maior nos animais mais musculosos ou bem-condicionados ${ }^{(13)}$. Fagliari et al. ${ }^{(18)}$ não verificaram influência da raça nas concentrações séricas de ureia (Ure) e creatinina (Crea) em bovinos da raça Nelore (Ure: 17,0 mg/dL e Crea: 1,60 mg/dL) e Holandesa (Ure: 19,8 mg/ dL e Crea: $1,65 \mathrm{mg} / \mathrm{dL}$ ). Cardoso et al. ${ }^{(17)}$ também não verificaram influência da raça nos teores desses metabólitos em bovinos das raças Curraleiro (Ure: 20,7 mg/dL e Crea: 1,16 mg/dL), Pantaneiro (Ure: 22,9 mg/dL e Crea: 1,19 mg/dL) e Nelore (Ure: 23,1 mg/dL; Crea: 1,28 mg/dL).

Notou-se influência dos fatores raciais nas concentrações de bilirrubina total (BT) e de bilirrubina indireta (BI), sendo os valores apresentados pelas vacas Nelore (BT: 0,28 mg/dL e BI: 0,19 mg/dL) superiores aos apresentados pelas vacas Girolando (BT: 0,23 mg/dL e BI: 0,14 mg/dL). Constatouse, ainda, que as concentrações de bilirrubina direta (BD) não diferiram entre os grupos (Tabela 1). Resultados semelhantes foram relatados por Souza et al ${ }^{\left({ }^{(8)}\right.}$. No referido estudo, as concentrações de BT e de BI foram maiores nos bovinos da raça Jersey (BT: 0,44 mg/dL e BI: 0,40 mg/dL), quando comparados com bovinos da raça Holandesa (BT: $0,25 \mathrm{mg} / \mathrm{dL}$ e BI: 0,22 mg/dL). Não houve influência racial nos valores de bilirrubina direta (Jersey: 0,04 mg/dL e Holandesa: 0,03 mg/dL). Pode-se afirmar que a variação observada no teor sérico de BT das vacas das raças Nelore e Girolando deveu-se à maior concentração de BI nos animais da raça Nelore. O nível de BI (bilirrubina desconjugada) depende diretamente da taxa de produção de bilirrubina, principalmente pela degradação de hemácias senescentes, e inversamente da captação e conjugação pelo fígado, que a transforma em BD (bilirrubina conjugada $)^{(15)}$.

As concentrações séricas de colesterol e triglicérides não foram influenciadas pela raça (Tabela 1). Contudo, Cardoso et al. ${ }^{(17)}$ verificaram maiores teores de colesterol no soro sanguíneo de bovinos das raças Nelore $(136,2 \mathrm{mg} / \mathrm{dL})$ e Pantaneiro $(87,7 \mathrm{mg} / \mathrm{dL})$, quando comparados com animais da raça Curraleiro $(69,7 \mathrm{mg} / \mathrm{dL})$.

Não foram constatadas diferenças entre os valores de cálcio total, fósforo, magnésio, sódio e potássio apresentados pelas vacas Nelore e Girolando. No entanto, as vacas Girolando $(0,73 \mathrm{mMol} / \mathrm{L})$ apresentaram uma maior concentração de cálcio ionizado quando comparadas às vacas da raça Nelore $(0,66 \mathrm{mMol} / \mathrm{L})$. Fagliari et al. ${ }^{(18)}$ também não verificaram influência da raça nos teores séricos de magnésio em bovinos da raça Nelore $(2,30 \mathrm{mg} / \mathrm{dL})$ e Holandesa $(2,33 \mathrm{mg} / \mathrm{dL})$. A variação observada nos teores séricos de cálcio ionizado das fêmeas bovinas das raças Nelore e Girolando pode estar relacionada à maior aptidão leiteira das vacas Girolando. $\mathrm{O}$ cálcio presente no sangue é formado por três frações: cálcio ionizado, cálcio ligado a proteínas séricas e cálcio complexado a ânions. $\mathrm{O}$ cálcio ionizado é a fração mais importante do ponto de vista biológico, representando cerca de $50 \%$ do cálcio total e desempenhando a função de íon regulador em vários processos metabólicos como coagulação sanguínea, contratilidade muscular e liberação de hormônios e neurotransmissores ${ }^{(15,19)}$.

Assim, os resultados obtidos evidenciaram a influência do fator racial na atividade sérica da enzima $\mathrm{CK}$ e nos teores séricos de creatinina, bilirrubina total, bilirrubina indireta e de cálcio ionizado de fêmeas bovinas sadias das raças Nelore e Girolando criadas no Maranhão. E as diferenças observadas nos estudos nacionais conduzidos por Souza et al. ${ }^{(8)}$, Cardoso et al. ${ }^{(17)}$ Fagliari et al. ${ }^{(18)}$, em relação ao presente estudo, provavelmente estão relacionadas com outros fatores que também podem influenciar o perfil bioquímico, como faixa etária dos animais, sexo, condições climáticas e de manejo ${ }^{(20)}$.

\section{Conclusões}

As diferenças observadas na atividade sérica da enzima creatina quinase (CK) e nos teores séricos de creatinina, bilirrubina total, bilirrubina indireta e de cálcio ionizado de fêmeas bovinas sadias 
das raças Nelore e Girolando indicam que o padrão racial é um dos fatores que deve ser levado em consideração para a correta interpretação de exames laboratoriais.

\section{Referências}

1. IBGE. Instituto Brasileiro de Geografia e Estatística. Produção da Pecuária Municipal 2016. 2017 Set [citado 2018 Mai 3]. Disponível em: https://agenciadenoticias.ibge.gov.br/agencia-noticias/2013-agencia-de-noticias/ releases/16992-pecuaria-municipal-2016-centro-oeste-concentra-34-4-do-rebanho-bovino-do-pais.html

2. Cassia C, Nobre G. Raças bovinas no Nordeste - características e ocorrência. Piracicaba: IBS - Instituto BioSistêmico; 2016. 22p.

3. González FHD, Scheffer J. Perfil sanguíneo: ferramenta de análise clínica, metabólica e nutricional. In: González FHD, Campos R. Anais do I Simpósio de Patologia Clínica da região Sul do Brasil. Porto Alegre: Gráfica da Universidade Federal do Rio Grande do Sul; 2003. p. 73-89.

4. Mundim AV, Costa AS, Mundim SAP, Guimarães EC, Espindola FS. Influência da ordem e estádios da lactação no perfil bioquímico sanguíneo de cabras da raça Saanen. Arquivo Brasileiro de Medicina Veterinária e Zootecnia. 2007;59(2):306-312.

5. Mundim AV, Coelho AO, Hortêncio SM, Guimarães EC, Espindola, FS. Influence of age and sex on the serum biochemical profile of Doberman dogs in the growth phase. Comparative Clinical Pathology. 2007;16(1):41-46

6. Oliveira MGC, Nunes TL, Paiva ALC, Bezerra TCG, Fernandes NS, Vale A.M, Barrêto Júnior RA, Paula VV. Aspectos hematológicos de caprinos (Capra hircus) da raça Canindé criados no Rio Grande do Norte. Pesquisa Veterinária Brasileira. 2012; 32(Supl.1):4-8.

7. Birgel Junior EH, Neves FS, Salvatore LCA, Mirandola, RMS, Távora JPF, Birgel EH. Avaliação da influência da gestação e do puerpério sobre a função hepática de bovinos da raça Holandesa. Ars Veterinaria. 2003;19(2):172-178.

8. Souza RM, Birgel Junior EH, Ayres MCC, Birgel EH. Influência dos fatores raciais na função hepática de bovinos da raça Holandesa e Jersey. Brazilian Journal of Veterinary Research and Animal Science. 2004; 41(5):306-312.

9. Dirksen G, Gründer HD, Stöber M. Rosenberger: exame clínico dos bovinos. $3^{\mathrm{a}}$ ed. Rio de Janeiro: Guanabara Koogan; 1993. 419p.

10. Weiss DJ, Wardrop K.J. Schalm's veterinary hematology. 6th ed. Iwoa: Wiley-Blackwell; 2010. 1206p.

11. Zar JH. Biostatistical analysis. 4th ed. New Jersey: Prentice Hall; 1999. 663p.

12. SAS Institute. Statistics Analysis System: user's guide. Version 9.1.3. Cary (NC). SAS Institute Inc., 2005.

13. Thrall MA. Hematologia e bioquímica clínica veterinária. São Paulo: Roca; 2007. 582p.

14. Morais MG, Rangel JM, Madureira JS, Silveira AC. Variação sazonal da bioquímica clínica de vacas aneloradas sob pastejo contínuo de Brachiaria decumbens. Arquivo Brasileiro de Medicina Veterinária e Zootecnia. 2000; 52(2):98-104.

15. Kaneko JJ, Harvey JW, Bruss M.L. Clinical biochemistry of domestic animals. 6th ed. San Diego: Academic Press; 2008. 916p.

16. Souza RM, Garcia NACR, Birgel DB, Birgel Junior EH. Influência do puerpério e da fase pós-puerperal na 
função hepática de vacas da raça Holandesa criadas no Estado de São Paulo. Ciência Animal Brasileira. 2008; 9(1):140-147.

17. Cardoso D, Costa MFO, Benatti LAT, Laudares KM, Vaz Júnior RG, Fioravanti MCS. Perfil bioquímico de bovinos de raças localmente adaptadas em sistema intensivo de criação. 2011 Jul [citado 2015 Jan 28]. Disponível em: http://www.sbpcnet.org.br/livro/63ra/conpeex/pivic/trabalhos/DANIELA_PDF

18. Fagliari JJ, Santana AE, Lucas FA, Campos Filho E, Curi PR. Constituintes sanguíneos de bovinos lactentes, desmamados e adultos das raças Nelore (Bos indicus) e Holandesa (Bos taurus) e de bubalinos (Bos bubalis) raça Murrah. Arquivo Brasileiro de Medicina Veterinária e Zootecnia. 1998; 50(3):263-271.

19. Lustoza MD, Kogika MM, Lazaretti P, Mirandola RMS. Avaliação dos valores séricos de cálcio ionizado pelo método eletrodo íon seletivo em cães hígidos. Arquivo Brasileiro de Medicina Veterinária e Zootecnia. $2005 ; 57(2): 177-180$.

20. Teixeira MG, Ferreira AF, Colaço AA, Ferreira SF, Benvenutti MEM, Queiroga FLPG. Hematologic and blood chemistry values of healthy Cebus flavius kept in northeast of Brazil. Journal of Medical Primatology. 2013; 42(2):51-56. 